\title{
Asphaltenes Size Polydispersity Reduction by Nano- and Ultrafiltration Separation Methods - Comparison with the Flocculation Method
}

\author{
J. Marques ${ }^{1 *}$, I. Merdrignac ${ }^{1}$, A. Baudot ${ }^{1}$, L. Barré ${ }^{2}$, D. Guillaume ${ }^{1}$, D. Espinat ${ }^{1}$ and S. Brunet ${ }^{3}$ \\ 1 Institut français du pétrole, IFP-Lyon, BP 3, 69390 Vernaison - France \\ 2 Institut français du pétrole, IFP-Rueil, 1-4, avenue de Bois-Préau, 92852 Rueil-Malmaison - France \\ 3 Laboratoire de chimie, 7B Catalyse en Chimie Organique, UMR 6503, Faculté des Sciences de I'Université de Poitiers, Poitiers - France \\ e-mail: joao.marques@ifp.fr - isabelle.merdrignac@ifp.fr - arnaud.baudoł@ifp.fr - loic.barre@ifp.fr - denisjm.guillaume@ifp.fr \\ didier.espinat@ifp.fr - sylvette.brunet@univ-poitiers.fr \\ * Corresponding author
}

\begin{abstract}
Résumé - Séparation des asphaltènes par nano et ultrafiltration - Comparaison avec la méthode de floculation - Les asphaltènes contiennent une multitude de composés très polydisperses en terme de composition chimique et en terme de taille, ce qui rend leurs propriétés et leur comportement difficiles à décrire. Afin de mieux caractériser ces espèces, une voie envisagée est de réduire cette polydispersité. Dans cette étude, nous avons proposé deux approches différentes : la floculation (en faisant appel à des solvants et anti-solvants) et la filtration membranaire. Les différentes fractions d'asphaltènes obtenues par chaque méthode sont caractérisées en utilisant les techniques suivantes : la chromatographie d'exclusion stérique (SEC), l'analyse élémentaire, la résonance magnétique nucléaire $\left(\mathrm{RMN}-{ }^{13} \mathrm{C}\right)$ et la diffusion des rayons $\mathrm{X}$ aux petits angles (SAXS). Il a été montré que des agrégats asphalténiques de différentes tailles peuvent être séparés par la filtration membranaire d'une façon plus sélective qu'en utilisant la méthode conventionnelle de floculation. Comparés aux grands agrégats, les petits agrégats asphalténiques présentent une aromaticité plus faible et un caractère aliphatique plus élevé. Leurs chaînes alkyles semblent être également plus courtes et plus ramifiées. De plus, l'analyse élémentaire indique que les plus petits asphaltènes contiennent une concentration inférieure en métaux et sont préférentiellement enrichis en vanadium plutôt qu'en nickel. Les effets de la température et de la concentration sur la performance de la séparation membranaire sont étudiés.
\end{abstract}

\footnotetext{
Abstract - Asphaltenes Size Polydispersity Reduction by Nano- and Ultrafiltration Separation Methods - Comparison with the Flocculation Method - Asphaltenes consist of a very complex material in which molecules and aggregates can have very different chemical composition and molecular weights. It is now well documented that asphaltenes show a very large size polydispersity. All these differences make their properties and behavior hard to describe. In order to gain insight into asphaltene properties, it could be useful to reduce this size polydispersity. Within this framework, two different approaches were used to reduce asphaltene size polydispersity: flocculation (using mixtures of solvents with anti-solvents) and membrane filtration. Various asphaltene fractions were obtained by both
} 
methods, and were further investigated using the following techniques: Size-Exclusion Chromatography (SEC), Elemental analysis, Nuclear Magnetic Resonance $\left({ }^{13} \mathrm{C}-N M R\right)$ and Small-Angle X-ray Scattering (SAXS). It has been shown that asphaltenic aggregates of different sizes can be fractionated by membrane filtration in a more selective way than using the conventional solvent flocculation method. The effects of temperature and concentration on membrane separation performance were studied. When compared with large aggregates, small asphaltenic aggregates present lower aromaticity and higher aliphatic composition. Their alkyl chains also appear to be shorter and more alkylated. Elemental analysis indicates that smaller asphaltenes contain a lower metal concentration and are preferentially enriched in vanadium than nickel when compared with bigger aggregates.

\section{INTRODUCTION}

Heavy oil properties such as high viscosity, high heteroatoms (sulfur and nitrogen) and metal contents may be related to the presence of asphaltenes. Asphaltenes are known to strongly influence industrial processes, such as, for instance, oil production, transportation, storage facilities and refining, particularly during hydroconversion. Successfully addressing the difficulties encountered during these processes needs a better understanding of heavy oil properties.

Asphaltenes are the most polar fraction of crude oil that precipitates in the presence of a high excess of a normal alkane $\left(\mathrm{nC}_{5}, \mathrm{nC}_{6}\right.$ or $\left.\mathrm{nC}_{7}\right)$ but are soluble in toluene [1]. The remaining fraction is called maltene.

The asphaltene fraction of the oil is commonly seen as a complex mixture of polydispersed molecules in terms of size and chemical composition [2-4]. These molecules have a tendency to aggregate depending on conditions such as the solvent, concentration, temperature, etc. Many analytical techniques have been used for their chemical and colloidal characterization, but the deduced average structural information is sometimes not very representative of the large variety of asphaltene species [5].

A detailed chemical characterization of asphaltenes is hard to achieve and may be a real limitation for the good understanding of the fundamental mechanisms in which they are involved during hydrotreatment/hydroconversion processes.

Size polydispersity of asphaltene macromolecules and aggregates has not been extensively investigated and some variations in the polydispersity can be highlighted as a function of heavy oil origin. Asphaltenes with different size or molecular weights may exhibit different catalytic conversion behaviors.

Thus, to gain insight into this domain, it is necessary:

- to investigate the size polydispersity of asphaltenes, and

- to isolate several monodispersed asphaltene fractions.

Several fractionation methods can be used. In this present work, we intended to produce n-heptane asphaltenes of reduced size polydispersity using two different techniques.
The first one was the flocculation method, based on the use of a mixture of a good solvent (toluene) and an anti-solvent (normal light paraffins, acetone, methanol), in different proportions [6-9]. In this work, we succeeded in preparing two different asphaltene fractions, the first one characterized by a low solubility (fraction with a high tendency to association) and the second one by a high solubility (fraction with a low tendency to association).

The second technique used was membrane filtration. Nanofiltration has been used to filtrate crude oil and bitumen at high temperatures without solvent addition [10]. It has been shown that asphaltenes can be selectively removed from these feeds. Other authors have performed this technique to study asphaltene diffusion properties. The concentration gradient is usually the driving force involved in asphaltene diffusion through porous membranes, allowing their size segregation $[11,12]$. In the present work pressure will be used as the driving force to separate asphaltenes of different sizes using ultra- and nanofiltration membranes.

In both ways, asphaltene fractions were characterized using different analytical techniques to obtain information regarding the aspects of asphaltene aggregate structure and composition.

\section{EXPERIMENT}

\subsection{Sample Preparation}

The asphaltenes used in this study were $\mathrm{n}$-heptane $\left(\mathrm{nC}_{7}\right)$ insoluble fractions of a Safaniya vacuum residue. The main properties of the Safaniya VR are summarized in Table 1.

In order to obtain a large amount of asphaltenes, vacuum residue deasphalting was processed in a temperature range from 210 to $230^{\circ} \mathrm{C}$ using a ratio of $\mathrm{n}$-heptane to vacuum residue equal to 8 . The mixture was stirred for one hour in a special homemade reactor unit and then settled for two hours in order to recover flocculated asphaltenes. The enriched flocculated asphaltene phase settles inside the reactor and the desaphalted VR phase was recovered on top of the reactor at a temperature close to $210^{\circ} \mathrm{C}$. Flocculated asphaltenes were 
TABLE 1

Characterization of Safaniya vacuum residue

\begin{tabular}{l|l}
\hline Density $\left(15^{\circ} \mathrm{C}\right)$ & 1.0290 \\
\hline Viscosity $100^{\circ} \mathrm{C}(\mathrm{cSt})$ & 1678 \\
\hline Viscosity $125^{\circ} \mathrm{C}(\mathrm{cSt})$ & 407.5 \\
\hline Conradson carbon (\%wt.) & 19.66 \\
\hline Elemental analysis & \\
\hline $\mathrm{S}(\% \mathrm{wt})$. & 5.11 \\
\hline $\mathrm{N}($ wt. ppm) & 3665 \\
\hline Ni (wt.ppm) & 43 \\
\hline $\mathrm{V}$ (wt. ppm) & 145 \\
\hline $\mathrm{H}(\%$ wt.) & 10.11 \\
\hline SARA analysis & \\
\hline Saturates (\%wt.) & 11.2 \\
\hline Aromatics (\%wt.) & 40.3 \\
\hline Resins (\%wt.) & 33.9 \\
\hline Asphaltenes $\mathrm{C}_{7}(\% \mathrm{wt})$. & 12.4 \\
\hline
\end{tabular}

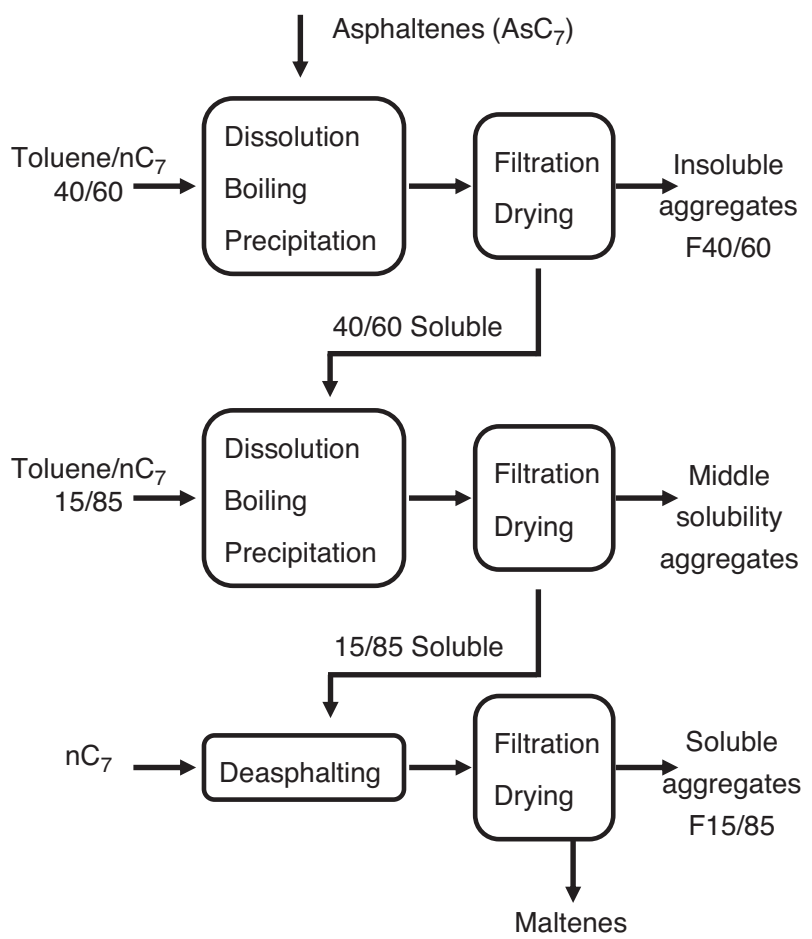

Figure 1

Asphaltene fractionation using several toluene/n-heptane mixtures. further recovered by addition of a large amount of toluene at $90^{\circ} \mathrm{C}$ inside the reactor. In order to remove the toluene, the previous solution of asphaltenes was submitted to $100^{\circ} \mathrm{C}$ (under a N2 atmosphere). After toluene evaporation, the obtained asphaltenes still contained $28 \%$ wt. of maltenes.

\subsection{Separation Methods}

\subsubsection{Flocculation}

The procedure is shown schematically in Figure 1. Asphaltenes were dissolved in a toluene/n-heptane mixture with a volume ratio of $40 / 60$ at a concentration of $25 \mathrm{~g} / \mathrm{L}$. The solution was heated up and refluxed for $1 \mathrm{~h}$. After cooling down for $1 \mathrm{~h}$ the suspension was then filtered using a Durapore PVDF $0.45 \mu \mathrm{m}$ filter. The precipitate was dried under vacuum and then in an oven at $60^{\circ} \mathrm{C}$, whereas the filtrated solvent was evaporated. The resulting insoluble fraction is called "F40/60".

The soluble fraction was then re-solubilized using a toluene/n-heptane mixture with a volume ratio of 15/85 and filtered. The corresponding filtrate fraction contains the most soluble asphaltenes and residual resins from the residue deasphaltening procedure. To remove these residual resins, the filtrate fraction is then deasphalted with n-heptane by using a derived method of the standard NF T60-115 method (equivalent to the IP143). The resulting fraction is called "F15/85".

\subsubsection{Membrane Filtration}

\section{Apparatus}

The experimental set-up consists of a small dead-end filtration cell housing flat membrane sheets. It admits up to $270 \mathrm{~mL}$ of solution, and displays $51.4 \mathrm{~cm}^{2}$ of active filtration surface. The cell is made of stainless steel and is equipped with a magnetic stirrer located just above the membrane surface. Toluene was found to be adequate for asphaltene dispersion and we verified its good compatibility with the membrane material.

\section{Experimental Procedure}

The asphaltene sample was first dissolved in toluene $(200 \mathrm{~mL})$. The solution was then submitted:

- to 10 bar feed pressure for ultrafiltration through a polyethersulfone porous membrane with a $20 \mathrm{kDa}$ molecular weight cut-off (MWCO) (UP020 membrane produced by NADIR and provided by Alting, Hoerdt France) and

- 30 bar using a $0.4 \mathrm{kDa}$ MWCO dense polyimide nanofiltration membrane (Starmem 240 membrane, provided by MET, Imperial College, London UK).

$20 \mathrm{kDa}$ MWCO membranes were calibrated by the supplier using polysaccharide and polyethylene glycol. Linear alkanes diluted in toluene were used for the $0.4 \mathrm{kDa} \mathrm{MWCO}$ membrane calibration. 
The filtrate and retentate (fraction collected in the feed compartment at the end of the filtration test) fractions were recovered and toluene was then removed by evaporation.

\subsection{Characterization of Asphaltene Fractions}

The different asphaltene fractions were characterized by sizeexclusion chromatography (SEC) for molecular weight distributions, small-angle X-ray scattering (SAXS) for average radius of gyration and molecular weight measurement, elemental analysis for $\mathrm{C}, \mathrm{H}, \mathrm{N}, \mathrm{S}, \mathrm{Ni}$ and $\mathrm{V}$ content determinations and nuclear magnetic resonance $\left({ }^{13} \mathrm{C}-\mathrm{NMR}\right)$ for structural characterization.

It is well known that SEC and SAXS results may differ because:

- The state of aggregation of asphaltenes is not the same in both experiments: (i) a different solvent is used (toluene in SAXS and THF in SEC) and (ii) SAXS measurements are carried out on rather highly concentrated asphaltene suspensions, a few percent of asphaltenes in toluene, instead of SEC experiments where the concentration of asphaltene entities flowing through the gel is probably very low (below a tenth of percent).

- SAXS measurement gives the average molecular weight $\left(M_{w}-\right.$ see formula 2$)$, which is very dependent on the largest molecules. SEC data are given in equivalent polystyrene (eq. PS.), and SEC fractionation is mainly dependent on the hydrodynamic volume of the molecule. So, in these experiments the hydrodynamic volume of one asphaltene molecule is compared with a polystyrene chain. There is evidence that the chemical structures of these entities are very different and thus different molecules can have a similar hydrodynamic volume, but not identical molecular weight. To gain insight into this field it would be necessary to perform a universal calibration [13] taking into account not the average molecular weight of asphaltenes and polystyrene standards but the product of the intrinsic viscosity and the molecular weight $([n] M)$. This needs the determination of the intrinsic viscosity of asphaltene molecules as a function of their molecular weight. Work is still in progress in this domain.

- Special adsorption effects exist on the SEC column, due to interaction between asphaltenes and crosslinked polystyrene support.

\subsubsection{Size-Exclusion Chromatography (SEC)}

SEC was performed on a Waters Alliance 2695 system, using a refractive index detector described elsewhere [14]. The system was controlled using an Empower chromatography manager. Calibration was performed using 10 monodisperse polystyrene standards with masses in the range of 162-120 000 g/mol (Polymer Laboratories). Samples were injected at a concentration of $5 \mathrm{~g} / \mathrm{L}$ in tetrahydrofuran (THF) with a volume of $50 \mu \mathrm{L}$. The temperature was adjusted to $40^{\circ} \mathrm{C}$ and the flow rate was fixed at $0.7 \mathrm{~mL} / \mathrm{min}$. Three columns that were packed with polystyrene-divinylbenzene supports (PS-DVB, Polymer Laboratories) were chosen; the corresponding porosities are 10,100 and 1000 nanometers. The column characteristics are the following: packing particle size, $d p=5 \mu \mathrm{m}$; column length, $L=300 \mathrm{~mm}$; and internal diameter, $8 \mathrm{~mm}$. The SEC data enable one to describe the weight distributions according to weight averages, calculated as follows:

$$
\begin{aligned}
M_{n}= & \frac{\sum N_{i} M_{i}}{\sum N_{i}} \\
M_{w}= & \frac{\sum N_{i} M_{i}^{2}}{\sum N_{i} M_{i}} \\
M_{z}= & \frac{\sum N_{i} M_{i}^{3}}{\sum N_{i} M_{i}^{2}} \\
M_{z+1}= & \frac{\sum N_{i} M_{i}^{4}}{\sum N_{i} M_{i}^{3}}
\end{aligned}
$$

where $N_{i}$ represents the number of molecules with a molecular weight of $M_{i}$. Basically, $M_{n}$ is more sensitive to low molecular weights, instead of higher orders of the distributions $\left(M_{w}, M_{z}\right.$ and $\left.M_{z}+1\right)$ which are sensitive to higher molecular weights.

\subsubsection{SAXS}

SAXS measurements were performed with a HuxleyHolmes-type camera. The X-ray beam was provided by a copper $(1.54 \AA$ ) rotating anode (Rigaku). The X-ray beam was focused by a curved mirror with a graded multilayer coating by Xenocs. A one-dimensional position-sensitive proportional counter (Elphyse) was used for X-ray spectrum recording. This detector has a resolution of $150 \mu \mathrm{m}$ (full width at half maximum). The $\mathrm{X}$-ray generator was operated at $1 \mathrm{~kW}(40 \mathrm{kV} \times 25 \mathrm{~mA})$. The range of wave vectors $(q)$ accessible was between 0.01 and $0.22 \AA^{-1}$. For the experiments, the samples were introduced into a 2-mm-diameter sealed glass capillary maintained in a temperature-controlled sample holder. After normalization in respect to thickness, transmission and measuring time, the solvent signal was subtracted from the sample signal. Experimental data were converted into an absolute scale. All the present experiments were conducted at $25^{\circ} \mathrm{C}$.

The scattering cross-section, $I(q)$, is measured as a function of the wave scattering vector $q$ defined by:

$$
q=\frac{4 \pi \times \sin \theta}{\lambda}
$$

where $\lambda$ is the wavelength and $2 \theta$ is the scattering angle. 
For a two-component system, such as a particle in a solvent (in our case, asphaltenes in toluene), a general expression of $I(q)$ can be derived:

$$
I(q)=\phi \cdot(1-\phi) \cdot \Delta \rho^{2} \cdot F(q) \cdot S(q)
$$

with $\phi$ : particle volume fraction, $\Delta \rho^{2}$ : contrast term (determined from density and chemical composition of solvent and particles), $F(q)$ : the form factor $(F(0)=v$, volume of the scattering particle) which is a function of the shape, size and polydispersity of particles and $S(q)$ : the structure factor which depends on the inter-particle interactions.

For dilute solutions of particles and without inter-particle interactions $(S(q)=1)$, in the Guinier region (for small $q$ values, that is to say, on scales larger than the typical size of particles), we can determine the scattering cross-section at zero angle, $I(0)$, and the radius of gyration of the particles thanks to Zimm's approximation:

$$
\frac{1}{I(q)}=\frac{1}{I(0)}\left(1+\frac{q^{2} R_{g}^{2}}{3}+\ldots\right), \text { for } q R_{g}<<1
$$

From Equation 6, $I(0)$ takes a simple form for dilute solutions from which the particle volume, $v$, can be extracted:

$$
\frac{I(0)}{\phi \Delta \rho^{2}}=v
$$

The "molar mass", $M$, can be derived by using the usual expression

$$
M=d N_{a} v
$$

with $d$ : the specific gravity of the solute and $N_{a}$ : the Avogadro number.

Combining Equations 7,8 and 9 one gets

$$
\frac{I_{e} \Delta \rho^{2}}{d^{2} N_{a}} \frac{c}{I(0)}=K \frac{c}{I(0)}=\frac{1}{M_{w}}
$$

The molar mass and the radius of gyration of particles were determined from a least-square linear fit of $1 / I(q)$ as a function of $q^{2}$ (Zimm plot).

\subsection{3 ${ }^{13} \mathrm{C}$ Nuclear Magnetic Resonance $\left({ }^{13} \mathrm{C}-\mathrm{NMR}\right)$}

NMR experiments were performed with an Advanced 300 $\mathrm{MHz}$ Bruker spectrometer, using a $10-\mathrm{mm}$ BBO ${ }^{1} \mathrm{H} / \mathrm{X} / \mathrm{D}$ NMR probe. The chemical shifts were referenced using $\mathrm{CDCl}_{3}$ as a solvent. Samples were prepared by mixing $100 \mathrm{mg}$ of asphaltenes in $3 \mathrm{~mL}$ of $\mathrm{CDCl}_{3}$ to obtain a homogeneous solution. ${ }^{13} \mathrm{C}$-NMR direct acquisition spectra were realized with a $60^{\circ}$ flip angle at a radio frequency pulse of $20 \mathrm{kHz}$, which provided the quantity of saturated and unsaturated carbon atoms. In addition, two ${ }^{13} \mathrm{C}-\mathrm{NMR}$ experiments, based on the scalar coupling between proton and carbons, were realized in order to obtain data about paraffinic, naphthenic and aromatic carbon species. The spin-echo experiment allowed the aromatic and aliphatic carbon species to be quantified separately, and the Attached Proton Test (APT) series was applied to identify and quantify the proportion of carbon atoms, as a function of the number of protons in their neighbourhood.

\section{RESULTS AND DISCUSSION}

\subsection{Separation by Flocculation}

F40/60 and F15/85 asphaltene fractions were obtained with yields of $20 \%$ wt. and $6 \%$ wt., respectively, when compared with the initial asphaltenes.

Results from SEC analysis indicate that asphaltene fractions of different solubilities differ from each other in their mass distribution (Fig. 2). The most soluble fraction (F15/85) is enriched in the smallest asphaltene aggregates, smaller than $4000 \mathrm{~g} / \mathrm{mol}$ in equivalent to polystyrene (eq. PS.), whereas the F40/60 fraction contains the largest asphaltene aggregates, larger than $20000 \mathrm{~g} / \mathrm{mol}$ (eq. PS.). However, a high polydispersity of asphaltene aggregates still exists for both asphaltene fractions. This indicates that the separation method by flocculation is not only sensitive to the size of the asphaltene aggregates, but also to other factors, such as chemical properties of the asphaltenes that can influence the separation efficiency.

The F40/60 asphaltene fraction presents a SEC mass profile similar to the initial fraction. As this fraction represents about $20 \%$ wt. of the initial asphaltenes, it is not surprising

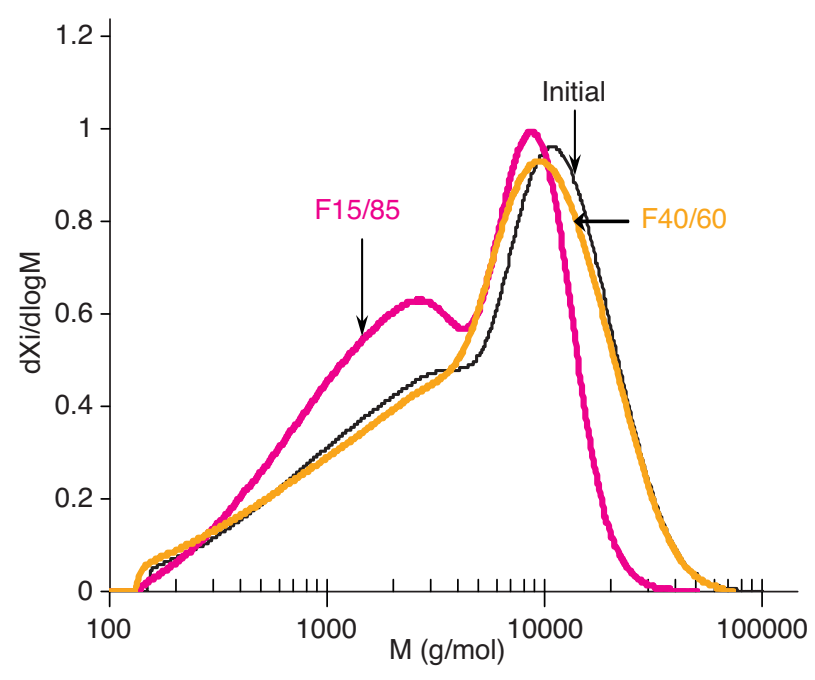

Figure 2

Mass distributions measured by SEC experiments of different asphaltene fractions obtained by flocculation separation. F15/85 - Most soluble fraction; F40/60 - Insoluble fraction. 
TABLE 2

Elemental analysis of different asphaltene fractions obtained by the flocculation method. F15/85 - Most soluble fraction; F40/60 - Insoluble fraction

\begin{tabular}{c|c|c|c|c|c|c|c}
\hline $\begin{array}{c}\text { Asphaltene } \\
\text { fractions }\end{array}$ & $\mathrm{H} / \mathrm{C}^{*}$ & $\mathrm{~N} / \mathrm{C}^{*}$ & $\mathrm{O} / \mathrm{C}^{*}$ & $\mathrm{~S} / \mathrm{C}^{*}$ & $\mathrm{Ni}(\mathrm{ppm})$ & $\mathrm{V}(\mathrm{ppm})$ & $\mathrm{Ni} / \mathrm{V}^{*}$ \\
\hline Initial & $1.076 \pm 0.027$ & $0.010 \pm 0.002$ & $0.013 \pm 0.001$ & $0.034 \pm 0.001$ & $195 \pm 7$ & $591 \pm 32$ & 0.29 \\
\hline $\mathrm{F} 40 / 60$ & $1.061 \pm 0.027$ & $0.011 \pm 0.002$ & $0.015 \pm 0.001$ & $0.035 \pm 0.001$ & $66 \pm 10$ & $212 \pm 12$ & 0.27 \\
\hline F15/85 & $1.160 \pm 0.027$ & $0.010 \pm 0.002$ & $0.010 \pm 0.001$ & $0.030 \pm 0.001$ & $173 \pm 6$ & $533 \pm 29$ & 0.28 \\
\hline * Atomic ratio.
\end{tabular}

that the SEC profile of this fraction is close to that of nonfractionated asphaltenes.

Average chemical and structural differences are found between the two fractions.

Table 2 shows that F15/85 asphaltene aggregates are more hydrogenated and more concentrated in metals ( $\mathrm{Ni}$ and $\mathrm{V}$ ) than F40/60 asphaltene aggregates, either in absolute terms or in comparison with the initial non-fractionated asphaltenes. However, nickel and vanadium are present in the same proportions $(\mathrm{Ni} / \mathrm{V}$ ratios) for both fractions. Concerning the heteroatoms $\mathrm{O}$ and $\mathrm{S}$, it seems that they are slightly more concentrated in the 40/60 fraction, whereas the $\mathrm{N}$ repartition is similar in both fractions.

Table 3 shows the ${ }^{13} \mathrm{C}$-NMR structural characterization results obtained for the two different asphaltene fractions. It shows that the insoluble fraction (F40/60) is likely to be less aliphatic and more aromatic than the most soluble fraction (F15/85). ${ }^{13} \mathrm{C}-\mathrm{NMR}$ results also reveal differences between these two fractions in their aromatic and aliphatic carbon skeletons. Aromatic carbons $\left(\mathrm{C}_{\mathrm{aro}}\right)$ from F40/60 asphaltene aggre-

TABLE 3

${ }^{13} \mathrm{C}-\mathrm{NMR}$ analysis results of different solubility classes of asphaltene fractions. F15/85 - Most soluble fraction; F40/60 - Insoluble fraction

\begin{tabular}{c|c|c|c}
\hline & Initial & $\mathrm{F} 40 / 60$ & $\mathrm{~F} 15 / 85$ \\
\hline $\mathrm{C}_{\text {aromatic }}$ (\%wt.) & $54 \pm 2$ & $54 \pm 2$ & $50 \pm 2$ \\
\hline $\mathrm{C}_{\text {aliphatic }}$ (\%wt.) & $46 \pm 2$ & $46 \pm 2$ & $50 \pm 2$ \\
\hline
\end{tabular}

Weight percentages in relation to Caro-total

\begin{tabular}{|c|c|c|c|c|}
\hline $\mathrm{C}_{\text {quaternary }}(\% \mathrm{wt})$. & substituted & $37 \pm 2$ & $48 \pm 2$ & $33 \pm 2$ \\
\hline & condensed & $34 \pm 2$ & $46 \pm 2$ & $33 \pm 2$ \\
\hline \multicolumn{2}{|c|}{$\mathrm{C}_{\mathrm{aro}}-\mathrm{H}$ (\%wt.) } & $29 \pm 2$ & $6 \pm 2$ & $34 \pm 2$ \\
\hline
\end{tabular}

Weight percentages in relation to Caliphatic-total

\begin{tabular}{c|c|c|c}
\hline $\mathrm{C}_{\text {quaternary }}$ (\%wt.) & 0 & 0 & 0 \\
\hline $\mathrm{CH}$ (\%wt.) & $13 \pm 3$ & $15 \pm 3$ & $11 \pm 3$ \\
\hline $\mathrm{CH}_{2}$ (\%wt.) & $64 \pm 3$ & $57 \pm 3$ & $65 \pm 3$ \\
\hline $\mathrm{CH}_{3}$ (\%wt.) & $23 \pm 3$ & $28 \pm 3$ & $23 \pm 3$ \\
\hline
\end{tabular}

gates seem to be on average more condensed and more substituted than those of F15/85 asphaltenes. It is straightforward to notice that the F40/60 fraction contains the lowest content of hydrogen atoms connected to aromatic carbons $\left(\mathrm{C}_{\mathrm{aro}}-\mathrm{H}\right)$.

Higher $\mathrm{CH}$ and $\mathrm{CH}_{3}$ combined with lower $\mathrm{CH}_{2}$ aliphatic carbon relative content suggests a possible trend for higher ramification and lower length of alkyl chains within F40/60 asphaltenes.

These results confirm that asphaltene flocculation seems to be driven by its aromatic character regarding its solubility/insolubility in a given more or less aromatic solvent.

Results obtained by other authors have previously shown that the solubility of asphaltenes was mainly related to either the aromaticity and aliphaticity factors or polarity of asphaltenes [15-21].

For these experimental conditions, asphaltene association might be ruled by intermolecular van der Waals interactions between their aromatic systems. The attached aliphatic chains may disrupt these interactions, avoiding flocculation. The balance between these two effects could thus control the flocculation, which would explain the obtained results. This is in agreement with solubility concepts proposed in other work [22].

In conclusion, the flocculated asphaltene fractions showed differences in terms of mass distribution and chemical structures. However, size polydispersity was not significantly reduced.

\subsection{Membrane Filtration}

\subsubsection{Effect of Experimental Conditions on Membrane Separation Efficiency}

The aggregation state of asphaltene macromolecules depends on the experimental conditions (concentration, temperature and solvent) [5]. It is obvious that modifications in the asphaltene aggregation state might affect the membrane filtration performance.

Membrane performance is evaluated in terms of size selectivity (followed by SEC) and asphaltene filtrate mass flux is determined as follows:

$$
\text { Asphaltene Flux }=\frac{\text { filtrated asphaltene masse }}{\text { filtration time } \times \text { membrane surface }}
$$


The asphaltene concentration and temperature effects were investigated using a $20 \mathrm{kDa}$ MWCO membrane.

\section{Effect of the Asphaltene Concentration}

The experiments showed that the yield of filtrated asphaltenes was higher for lower initial asphaltene concentrations (Table 4). This indicates that the filtration of the small aggregates is not totally completed during these experiments.

\section{TABLE 4}

Filtration yield (amount of filtrated asphaltenes divided by the total amount of asphaltenes introduced into the filtration cell) as a function of asphaltenes initial concentration (using a $20 \mathrm{kDa}$ MWCO membrane, $25^{\circ} \mathrm{C}$ )

\begin{tabular}{c|c}
\hline $\begin{array}{c}\text { Initial asphaltene concentration } \\
\text { of the solution introduced into } \\
\text { the filtration cell (\%wt.) }\end{array}$ & $\begin{array}{c}\text { Filtration yield of filtrated } \\
\text { asphaltene fraction } \\
(\% \mathrm{wt} .)\end{array}$ \\
\hline 2.2 & 1.7 \\
\hline 0.8 & 3.7 \\
\hline 0.1 & 7.8 \\
\hline
\end{tabular}

SEC results of asphaltene fractions collected from tests performed at three different initial concentrations $(0.1,0.8$ and 2.2\%wt.) are presented in Figure 3. It clearly shows that no modification in the size polydispersity of these asphaltene fractions was detected. We can conclude that the asphaltene concentration of the solution prepared for filtration experi- ments, in the range of $0.1 \%$ wt. to $2.0 \%$ wt., has no effect on the fractionation process. Thus, it seems reasonable to assert that within these concentrations asphaltenes are in a diluted regime and the filtration of small asphaltenes will not be modified by the concentration. It probably will not be the case for higher asphaltene concentrations where the asphaltene aggregation state might be affected.

We investigated the size polydispersity of filtrated asphaltene fractions as a function of the filtration time. Figure 4 represents three samplings of filtrated fraction at different times $\left(t_{1}<t_{2}<t_{3}<t_{4}\right)$. The differences between the size distribution of filtrated asphaltenes collected at time " $t_{1}$ " and asphaltenes collected at times " $t_{2}, t_{3}$ and $t_{4}$ " can be interpreted as a consequence of the initial membrane non-steady state caused by its pressurization. As the pressure applied to the membrane increases, we can suggest pore contraction limiting the diffusion of bigger asphaltene aggregates. This flux reduction phenomenon might be induced by a possible sweeping of the conditioning agents from the dense selective layer of the $0.4 \mathrm{kDa}$ nanofiltration membrane by toluene or by the compaction of the porous selective layers of the $20 \mathrm{kDa}$ ultrafiltration membrane, as shown by other authors [23]. It must be mentioned here that no significant surface fouling was observed when dismounting the permeation cell at the end of the experiments.

Figure 5 represents asphaltene flux as a function of the concentration of the retained fraction. For each sample the retained asphaltene concentration was estimated by the asphaltene mass balance.

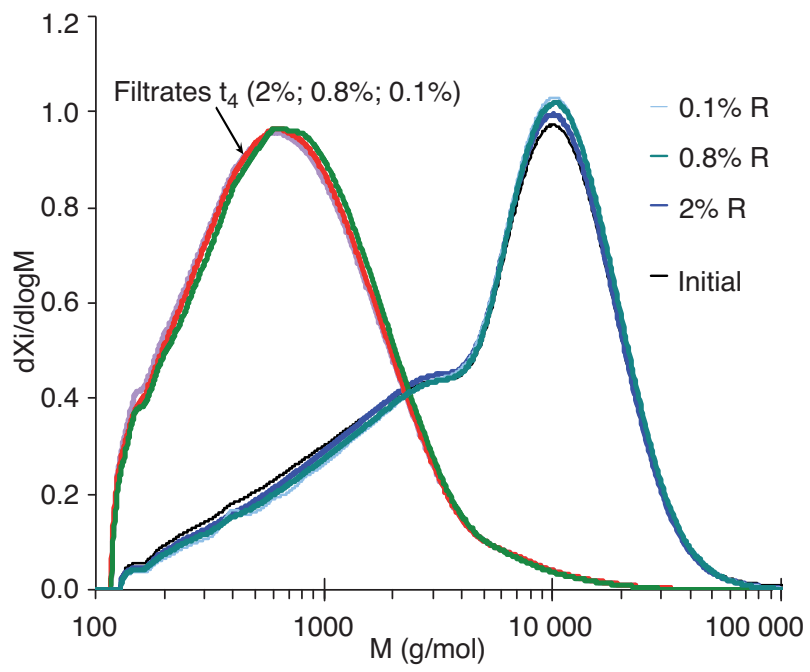

Figure 3

SEC mass distribution for retained and filtrated asphaltene fractions obtained after membrane filtration $(20 \mathrm{kDa}, 10 \mathrm{bar}$, $\left.25^{\circ} \mathrm{C}\right)$ of three different asphaltene solutions $(0.1,0.8,2 \% \mathrm{wt}$.).

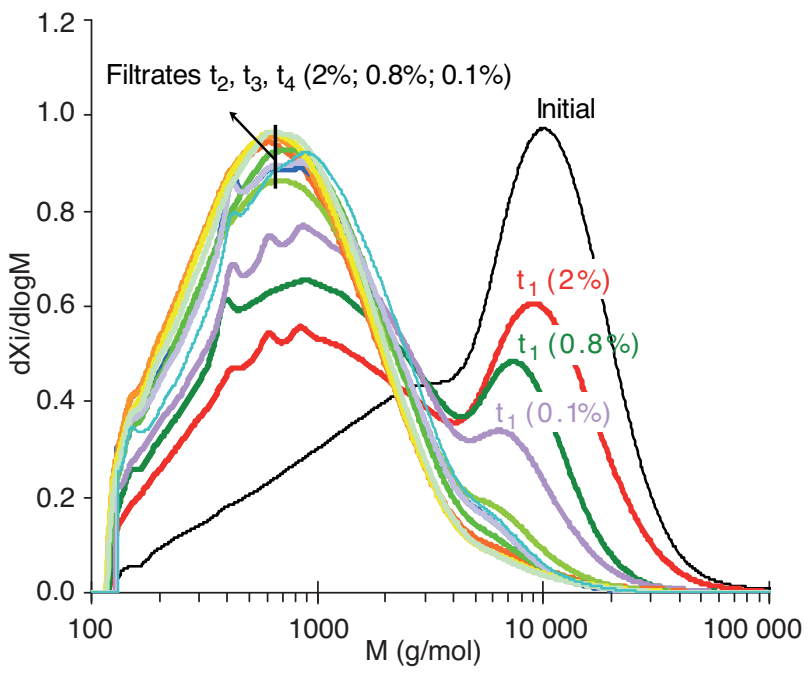

Figure 4

SEC mass distribution of filtrated asphaltene fractions collected at different times $t_{1}<t_{2}<t_{3}<t_{4}$ (initial concentration of asphaltenes: $0.8 \%$ wt., $20 \mathrm{kDa}, 10 \mathrm{bar}, 25^{\circ} \mathrm{C}$ ). 


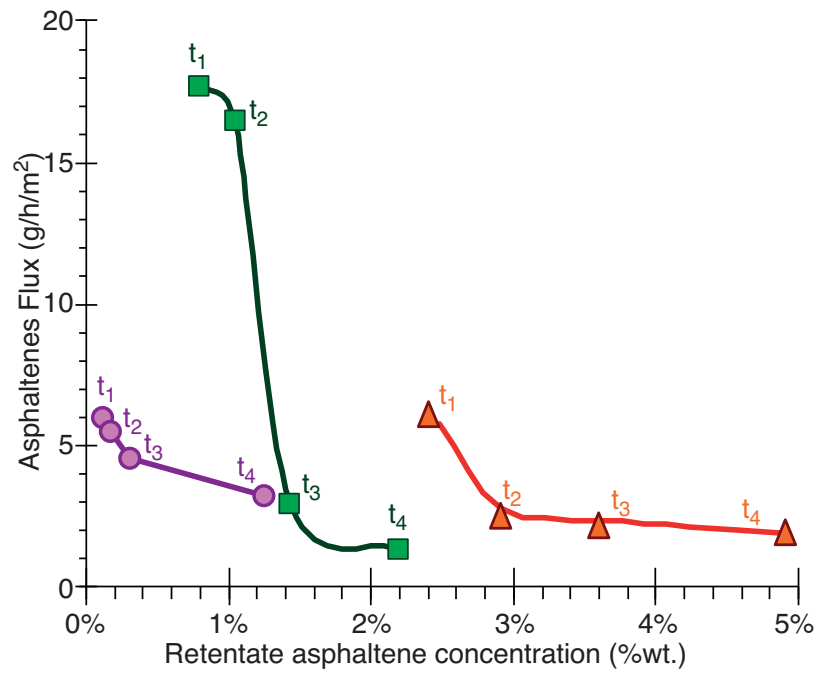

Figure 5

Asphaltene flux as a function of retained asphaltene concentration for tests starting with different initial asphaltene concentrations in toluene $(\bigcirc) 0.1 \%$ wt., $(\square) 0.8 \%$ wt. and $(\triangle) 2.2 \%$ wt., for several sampling times $t_{1}<t_{2}<t_{3}<t_{4}$ and using a $20 \mathrm{kDa}$ MWCO Membrane, $10 \mathrm{bar}, 25^{\circ} \mathrm{C}$.

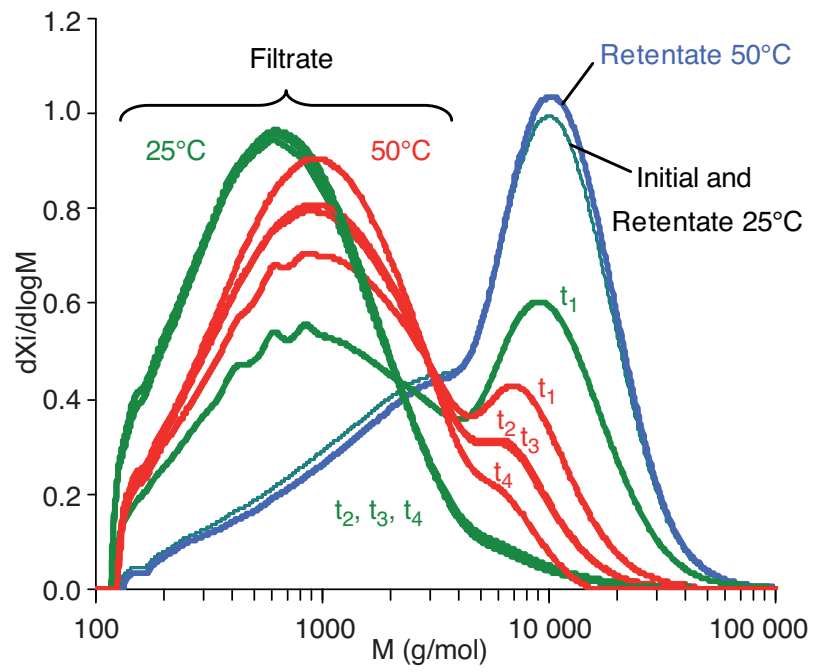

Figure 6

SEC size distributions for asphaltene fractions obtained by ultrafiltration at two different temperatures $\left(25^{\circ} \mathrm{C}\right.$ and $\left.50^{\circ} \mathrm{C}\right)$ using a $20 \mathrm{kDa}$ MWCO membrane, $10 \mathrm{bar}, 2 \%$ wt. initial asphaltene concentration. Evolution of size polydispersity as a function of time $\left(t_{1}<t_{2}<t_{3}<t_{4}\right)$.
As previously indicated, sample " $t$ " was collected during the membrane pore contraction due to initial pressurization. This explains why sample " $t_{1}$ " was filtrated with higher flux. The test starting at $0.8 \%$ wt. initial concentration presents a distinct initial flux from the other tests, even for sample " $t_{2}$ ". We have no clear explanation of this experimental result but we can suggest a defect in the membrane stabilization.

Figure 5 also indicates that the asphaltene flux tends to decrease with time-on-stream and then to stabilize at 1 to $3 \mathrm{~g} / \mathrm{h} / \mathrm{m}^{2}$ (samples " $t_{3}$ " and " $t_{4}$ "). Comparing the three tests in steady state (samples " $t_{3}$ " and " $t_{4}$ "), we can see that asphaltene flux is not dependent on the retentate asphaltene concentration. The flux decrease with filtration time can be interpreted as a consequence of membrane compaction at the beginning of the experiment, and not as an effect of asphaltene aggregation derived from concentration increase in the retentate.

\section{Effect of Temperature on Membrane Performance}

As temperature plays an important role in asphaltene aggregation [5], tests were performed at two different temperatures $\left(25\right.$ and $\left.50^{\circ} \mathrm{C}\right)$.

Filtrate asphaltenes were obtained with $1.7 \%$ wt. yield at $25^{\circ} \mathrm{C}$ and $6 \%$ wt. yield at $50^{\circ} \mathrm{C}$.

The SEC results presented in Figure 6 show that a temperature increase affects membrane selectivity, increasing SEC molar masses of filtrated asphaltenes. We can propose several interpretations for these experiments:
- A temperature effect: it is well known that asphaltene aggregates self-dissociate with the increase in the temperature. At $50^{\circ} \mathrm{C}$, the asphaltenes of the initial solution are in a more pronounced dissociated state (smaller aggregates) than at $25^{\circ} \mathrm{C}$, allowing their filtration through the membrane. In SEC analytical conditions (different solvent and temperature), dissociated asphaltenes could re-associate. This dissociation - association phenomenon could explain SEC chromatograms.

- Membrane deformation: the membrane swelling can be modified by temperature, which can significantly influence its selectivity. The membrane swelling increase with temperature makes the steady state hard to achieve (progressive membrane compacting), explaining why samplings at various times $\left(t_{2}, t_{3}\right.$ and $\left.t_{4}\right)$ obtained at $50^{\circ} \mathrm{C}$ are different. This is supported by Figure 7 showing that flux drops considerably with time-on-stream for the $50^{\circ} \mathrm{C}$ test, meaning a steady state is hard to achieve, probably due to membranes lack of rigidity. Other explanations for this could be a fouling effect or a concentration polarization phenomenon, which are less probable at $50^{\circ} \mathrm{C}$.

In conclusion, for higher temperatures higher filtration yields are achieved. At $50^{\circ} \mathrm{C}$ a higher filtrated asphaltene polydispersity is obtained. Membrane swelling is the most probable cause of this and not asphaltene dissociation, because asphaltene filtrate fluxes are also deeply affected during the test. 


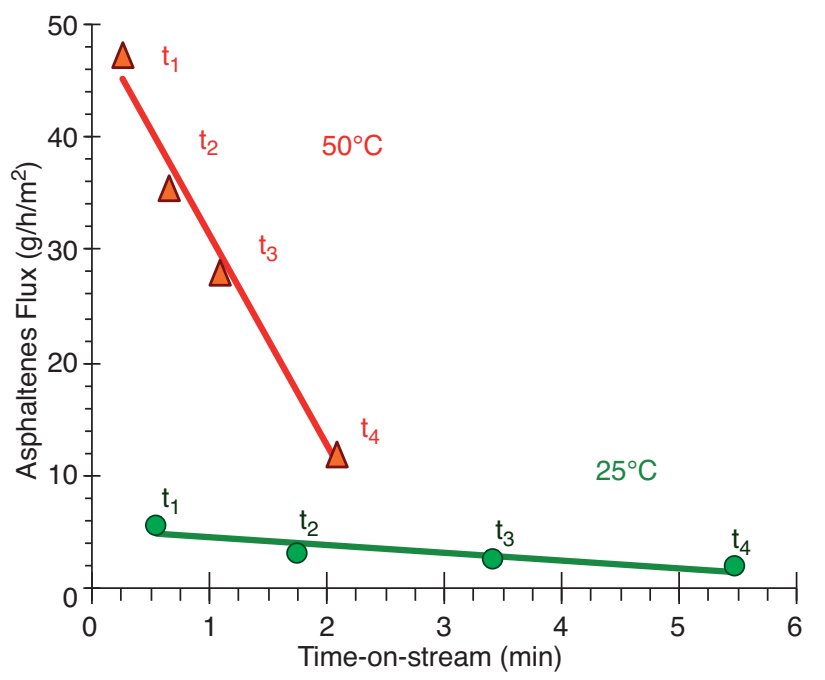

Figure 7

Asphaltene flux as a function of time-on-stream for filtration tests performed at different temperatures $(\bigcirc) 25^{\circ} \mathrm{C},(\triangle)$ $50^{\circ} \mathrm{C}$, using a $20 \mathrm{kDa}$ MWCO membrane, $10 \mathrm{bar}, 25^{\circ} \mathrm{C}$, $2 \%$ wt. initial asphaltene concentration.

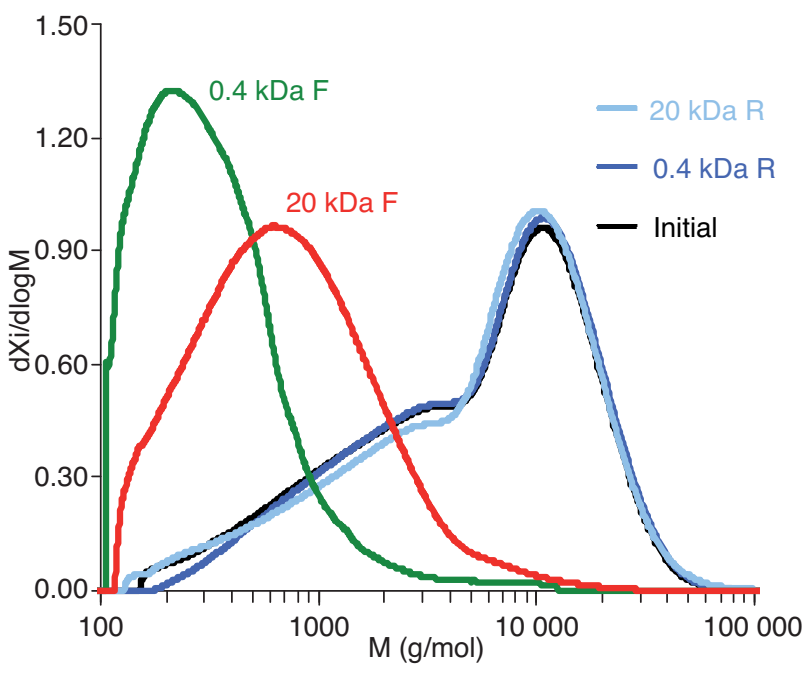

Figure 8

SEC chromatograms of the retained and filtrated asphaltene fractions for two filtration tests: Nanofiltration $(0.4 \mathrm{kDa}$ MWCO membrane, $\left.30 \mathrm{bar}, 25^{\circ} \mathrm{C}\right)$; Ultrafiltration $(20 \mathrm{kDa}$ MWCO membrane, 10 bar, $25^{\circ} \mathrm{C}$ ); R - Retained asphaltenes; F- Filtrated asphaltenes.

\subsubsection{Effect of Membrane Cut-off on Size Selectivity and Asphaltene Fractions Detailed Characterization}

In order to obtain asphaltenes with reduced size distribution, several membranes with different MWCO were used.

Filtrate asphaltenes were obtained with $0.5 \%$ yield using a $0.4 \mathrm{kDa}$ MWCO nanofiltration membrane and $1.7 \%$ yield using a $20 \mathrm{kDa}$ MWCO ultrafiltration membrane.

SEC mass distributions are presented in Figure 8. We can observe that both membranes were selective to small asphaltene aggregates, allowing a significant size polydispersity reduction.

With nanofiltration using a $0.4 \mathrm{kDa}$ polyimide membrane, an asphaltene filtrate fraction exhibits a sharp molecular weight distribution whose maximum is close to $200-400 \mathrm{~g} / \mathrm{mol}$ eq. PS. With ultrafiltration an asphaltene filtrate fraction was also obtained containing small aggregates. The distribution is maximal close to $1000 \mathrm{~g} / \mathrm{mol}$ eq. PS. The largest aggregates are concentrated in the retentate fractions.

These results show that membrane filtration can be used to prepare asphaltene fractions with controlled mass distributions.

A detailed characterization of fractionated asphaltene families can provide key information to understand asphaltenes chemistry and their fundamental mechanism of aggregation. The results presented next reveal chemical and structural characteristics of asphaltene aggregates differing in their size. Only the fractions obtained from ultrafiltration $(20 \mathrm{kDa}$, $10 \mathrm{bar}, 25^{\circ} \mathrm{C}$ ) were further characterized because nanofiltration $\left(0.4 \mathrm{kDa}, 30 \mathrm{bar}, 25^{\circ} \mathrm{C}\right)$ yield was too low to collect a sufficient quantity of the filtrate sample.
In order to complete the mass profiles (in eq PS) obtained by SEC, SAXS measurements were performed to determine absolute average masses of asphaltene aggregates. The obtained results are presented in Table 5. These data show a significant difference between retained and filtrated average aggregate sizes. SAXS indicates that retained aggregates have a much higher radius of gyration than filtrate aggregates, corresponding, respectively, to molecular weights of 310000 and $19000 \mathrm{~g} . \mathrm{mol}^{-1}$. These mass results obtained by SAXS are in good agreement with the membrane cut-off used.

Great differences between mass values obtained by SAXS and those obtained by SEC were observed. Several interpretations for these discrepancies are presented in Section 1.3.

In spite of these variations in the molecular weight determination, we can highlight the same tendencies of SAXS and SEC results.

TABLE 5

SAXS characterization results for initial, retained and filtrated asphaltene fractions obtained by ultrafiltration (20 kDa MWCO membrane, 10 bar, $\left.25^{\circ} \mathrm{C}\right)-R_{G}$ is the average radius of gyration and $M$ is the average molecular weight

\begin{tabular}{l|c|c}
\hline Fraction & $R_{G}(\AA)$ & $M\left(\mathrm{~g} \cdot \mathrm{mol}^{-1}\right)$ \\
\hline Initial & 85 & 217000 \\
\hline Retentate & 97 & 310000 \\
\hline Filtrate & 49 & 19000 \\
\hline
\end{tabular}


TABLE 6

Results of elemental analysis for initial, retained and filtrated asphaltene fractions obtained by ultrafiltration $\left(20 \mathrm{kDa} \mathrm{MWCO}\right.$ membrane, $\left.10 \mathrm{bar}, 25^{\circ} \mathrm{C}\right)$

\begin{tabular}{c|c|c|c|c|c|c|c}
\hline $\begin{array}{c}\text { Asphaltene } \\
\text { fractions }\end{array}$ & $\mathrm{H} / \mathrm{C}^{*}$ & $\mathrm{~N} / \mathrm{C}^{*}$ & $\mathrm{O} / \mathrm{C}^{*}$ & $\mathrm{~S} / \mathrm{C}^{*}$ & $\mathrm{Ni}(\mathrm{ppm})$ & $\mathrm{V}(\mathrm{ppm})$ & $\mathrm{Ni} / \mathrm{V} *$ \\
\hline Initial & $1.076 \pm 0.027$ & $0.010 \pm 0.002$ & $0.013 \pm 0.001$ & $0.034 \pm 0.001$ & $195 \pm 7$ & $591 \pm 32$ & 0.29 \\
\hline Retentate & $1.098 \pm 0.027$ & $0.010 \pm 0.002$ & $0.014 \pm 0.001$ & $0.035 \pm 0.001$ & $185 \pm 7$ & $555 \pm 30$ & 0.30 \\
\hline Filtrate & $1.136 \pm 0.027$ & $0.008 \pm 0.002$ & $0.023 \pm 0.001$ & $0.035 \pm 0.001$ & $68 \pm 2$ & $271 \pm 15$ & 0.22 \\
\hline * Atomic ratio.
\end{tabular}

TABLE 7

${ }^{13} \mathrm{C}$-NMR analysis results $-20 \mathrm{kDa}$ membrane filtration fractions

\begin{tabular}{c|c|c|c}
\hline & Initial & Retentate & Filtrate \\
\hline $\mathrm{C}_{\text {aromatic }}$ (\%wt.) & $54 \pm 2$ & $50.6 \pm 2$ & $48.1 \pm 2$ \\
\hline $\mathrm{C}_{\text {aliphatic }}$ (\%wt.) & $46 \pm 2$ & $49.4 \pm 2$ & $51.9 \pm 2$ \\
\hline
\end{tabular}

Weight percentages in relation to $\mathrm{C}_{\text {aro-total }}$

\begin{tabular}{|c|c|c|c|c|}
\hline $\mathrm{C}_{\text {quaternary }}(\% \mathrm{wt})$. & substituted & $37 \pm 2$ & $34 \pm 2$ & $40 \pm 2$ \\
\hline & condensed & $34 \pm 2$ & $39 \pm 2$ & $28 \pm 2$ \\
\hline \multicolumn{2}{|c|}{$\mathrm{C}_{\mathrm{aro}}-\mathrm{H}$ (\%wt.) } & $29 \pm 2$ & $27 \pm 2$ & $32 \pm 2$ \\
\hline
\end{tabular}

Weight percentages in relation to $\mathrm{C}_{\text {aliphatic-total }}$

\begin{tabular}{c|c|c|c}
\hline $\mathrm{C}_{\text {quaternary }}(\%$ wt.) & 0 & 0 & 0 \\
\hline $\mathrm{CH}$ (\%wt.) & $13 \pm 3$ & $13 \pm 3$ & $17 \pm 3$ \\
\hline $\mathrm{CH}_{2}$ (\%wt.) & $64 \pm 3$ & $65 \pm 3$ & $52 \pm 3$ \\
\hline $\mathrm{CH}_{3}$ (\%wt.) & $23 \pm 3$ & $23 \pm 3$ & $31 \pm 3$ \\
\hline
\end{tabular}

Table 6 shows that aggregates from filtrate fraction tend to be more hydrogenated (higher $\mathrm{H} / \mathrm{C}$ ). Nitrogen and sulfur contents are almost equal for both fractions in relation to their carbon content. Oxygen appears in higher proportion in smaller asphaltene aggregates. However, small aggregates from the filtrate fraction present lower metal concentration and it seems that they tend to concentrate preferentially vanadium than nickel when compared with large aggregates from the retained fraction.

Table 7 presents the obtained ${ }^{13} \mathrm{C}-\mathrm{NMR}$ characterization results. Small aggregates from the filtrate fraction present an aromatic/aliphatic repartition quite similar (within the experimental error) to the retentate fraction. Their aromatic structure is more substituted and less condensed in comparison with large aggregates. For small aggregates (filtrate), high $\mathrm{CH}$ and $\mathrm{CH}_{3}$ and low $\mathrm{CH}_{2}$ aliphatic carbon relative contents indicate a tendency to have more ramified and shorter aliphatic chains.

\section{CONCLUSION}

We need a better characterization of asphaltenes in order to improve our knowledge on hydrotreatment processes and to develop new catalysts. One way to characterize asphaltenes better is to reduce size polydispersity. In consequence, fractionation methods prior to characterization can be used to obtain key information about their structure and chemical composition. In this work, we studied two approaches for reducing the size polydispersity of an asphaltene fraction.

The flocculation method using solvent (toluene) and antisolvent $\left(\mathrm{nC}_{7}\right)$ mixtures in different proportions was used to separate extreme solubility fractions of asphaltene aggregates. It was found that these two extreme solubility fractions (soluble fraction-F15/85 and insoluble fraction-F40/60) mainly differ in their $\mathrm{H} / \mathrm{C}$ ratio, nickel and vanadium content and average chemical structure. The F15/85 fraction compared with the F40/60 fraction has a tendency to concentrate small aggregates but with no significant size polydispersity reduction.

Within this framework asphaltene membrane filtration was used. It was found that nano- and ultrafiltration separation methods allow one to separate asphaltene aggregates with higher size selectivity. The smallest asphaltene aggregates show higher hydrogen content and lower metal concentration. It was shown that metals may be concentrated at different proportions in distinct molecular size ranges (filtrate versus retentate fractions). A higher tendency is found for small aggregates (filtrate fraction) to concentrate preferentially vanadium than nickel in comparison with bigger asphaltene aggregates.

To evaluate how the asphaltene aggregation state might affect the filtration results, tests were done using different temperatures. The effect of the asphaltene concentration was also investigated. The results show that selectivity and filtrated asphaltene flux are not sensitive to concentration changes. However, the temperature was found to affect membrane selectivity and flux. For high temperatures, asphaltene flux is higher but not stable, which is attributed to membrane swelling, possibly caused by temperature. This also explains the increase in filtrated size polydispersity (followed by SEC) which could also be attributed to the asphaltene de-aggregation phenomenon.

The obtained data about the evolution of structure, chemical composition and metal distribution in asphaltenes of different sizes could be helpful for the creation of new hydrodemetallization catalysts and processes dealing with asphaltene conversion. 


\section{REFERENCES}

1 Speight J.G. (1999) The Chemistry and Technology of Petroleum, 3rd ed., Dekker, New York.

2 Szewczyk V., Behar F., Behar E., Scarsella M. (1996) Evidence of the physicochemical polydispersity of asphaltenes, Revue de l'Institut Français du Pétrole 51, 4, 575-590.

3 Mullins O.C., Groenzin H. (2000) Molecular size and structure of asphaltenes from various sources, Energ. Fuel. 14, 3, 677-684.

4 Sheu E.Y. (2002) Petroleum asphaltene - Properties, characterization and issues, Energ. Fuel. 16, 1, 74-82.

5 Merdrignac I., Espinat D. (2007) Physicochemical characterization of petroleum fractions: The state of the art, Oil Gas Sci. Technol. 62, 1, 7-32.

6 Andersen S.I. (1994) Dissolution of solid Boscan asphaltenes in mixed solvents, Fuel Sci. Technol. Int. 12, 11-12, 1551-1557.

7 Andersen S.I., Keul A., Stenby E. (1997) Variation in composition of subfractions of petroleum asphaltenes, Petrol. Sci. Technol. 15, 7-8, 611-645.

8 Lira-Galeana C., Buenrostro-Gonzalez E., Garcia-Martinez J.A., Andersen S.I. (2002) Solubility/molecular structure relationships of asphaltenes in polar and nonpolar media, Energ. Fuel. 16, 3 , 732-741.

9 Mullins O.C., Eser S., Mathews J., Yang M.G., Jones D., Groenzin H. (2003) Molecular size of asphaltene solubility fractions, Energ. Fuel. 17, 2, 498-503.

10 Zhao B., Chodakowski M.G., Hasan M.A., Fulem M., Lange C.F., Shaw J.M. (2007) Molecular Structure of Heavy Oils and Coal Liquefaction Products, Les Rencontres Scientifiques de l'IFP, Abstract Volume.

11 Baltus R.E., Anderson J.L. (1983) Hindered diffusion of asphaltenes through microporous membranes, Chem. Eng. Sci. 38, 12, 1959-1969.

12 Sane R.C., Tsotsis T.T. (1988) Hondo asphaltene diffusion in microporous track-etched membranes, 196th ACS Natl. Meet., pp. 237-247.
13 Allcock H.R., Lampe F.W., Mark J.E. (2003) Contemporary Polymer Chemistry, Pearson Education, Inc., New Jersey.

14 Merdrignac I., Truchy C., Robert E., Guibard I., Kressmann S.P. (2004) Size exclusion chromatography: Characterization of heavy petroleum residues. Application to resid desulfurization process, Petrol.Sci. Technol. 22, 7-8, 1003-1022.

15 Andersen S.I. (1997) Separation of asphaltenes by polarity using liquid-liquid extraction, Petrol. Sci. Technol. 15, 1-2, 185-198.

16 Andersen S.I., Keul A., Stenby E. (1997) Variation in composition of subfractions of petroleum asphaltenes, Petrol. Sci. Technol. 15, 7-8, 611-645.

17 Sharma B.K., Tyagi O.S., Aloopwan M.K.S., Bhagat S.D. (2000) Spectroscopic characterization of solvent soluble fractions of petroleum vacuum residues, Petrol. Sci. Technol. 18, 3-4, 249-272.

18 Sharma B.K., Stipanovic A., Tyagi O.S. (2000) Preprints ACS, 220th Nat. Meet., Div. Petr. Chem. 45, 4, 643.

19 Neves G.B.M., de Sousa M.D., Travalloni-Louvisse A.M., Lucas E.F., Gonzalez G. (2001) Characterization of asphaltene particles by light scattering and electrophoresis, Petrol. Sci. Technol. 19, $1-2,35-43$.

20 Andersen S.I., Lira-Galeana C., Stenby E.H. (2001) On the mass balance of asphaltene precipitation, Petrol. Sci. Technol. 19, 3-4, 457-467.

21 Wattana P., Fogler H.S., Yen A., Garcia M.D., Carbognani L. (2005) Characterization of polarity-based asphaltene subfractions, Energ. Fuel. 19, 1, 101-110.

22 Buenrostro-Gonzalez E., Groenzin H., Lira-Galeana C., Mullins O.C. (2001) The overriding chemical principles that define asphaltenes, Energ. Fuel. 15, 4, 972-978.

23 White L.S., Nitsch A.R. (2000) Solvent recovery from lube oil filtrates with a polyimide membrane, J. Membrane Sci. 179, 1-2, 267-274.

Final manuscript received in November 2007 or distributed for profit or commercial advantage and that copies bear this notice and the full citation on the first page. Copyrights for components of this work owned by others than IFP must be honored. Abstracting with credit is permitted. To copy otherwise, to republish, to post on servers, or to redistribute to lists, requires prior specific permission and/or a fee: Request permission from Documentation, Institut français du pétrole, fax. +33147527078 , or revueogst@ifp.fr. 